V.

\title{
Über Ablagerung und Resorption von Kalksalzen in den Geweben.
}

\author{
Von \\ Franz Hofmeister, Strassburg i./E.
}

Literatur.

1. Abderhalden, E., Zur vergleichenden Analyse des Blutes. Zeitschr. f. physiol. Chemie. 25, 67. 1898.

1a. Derselbe, Physiologische Chemie. 2. Aufl. 732. 1909.

2. Aron, H., Über den Einfluss der Alkalien auf das Knochenwachstum. Pflügers Archiv. 106, 91. 1905.

2. Asch off, L., Verkalkung. Ergebnisse d. allg. Pathol, herausgegeben von Lubarseh a. Ostertag. 8, 561. 1904.

4. A skanazy, M., Beiträge zur Knochenpathologie. Festsehr. f. J a f fé. Braunschweig 1901.

5. Beer, Edw., Lime deposits, especially the so called Kalkmetastasen in the Kidneys. Journ. of Path. and Bacteriology. 9. 225. 1904.

6. Bottazzi, E., Physiolog. Chemie. Deutseh von Boruttau. 1. 56. 1902.

7. Chiari, Hans, Über einen Fall von pathologiseher Kalkablagerung in den Lungen und Nieren. Wien. med. Wochenschr. 1878. 6.

8. Cohnheim und Maas, Zur Theorie der Geschwulstmetastasen. Virchows Arch. 70, 161. 1877.

9. Czapek, Friedrich, Jahrb. f. wiss. Bot. 29, 381. 1896.

10. Czech, E., Über Kalkmetastasen. I.-D. Würaburg 1895.

11. Davidsohn, C, Fragmentation der elastischen Fasern. Virchows Archiv. 160, 538. 1900.

12. Derselbe, Kalkablagerung mit Fragmentation der elastischen Fasern beim Hunde. Arbeiten a. d. pathol. Institut zu Berlin. 1906. 504.

13. Flesch, M., Zur Physiologie der Knochenresorption. Zentralb]. f. d. med. Wiss. 1876. 524.

14. Fokker, A. P., Vorkommen von gelösten Erden und Phosphorsäure im alkalischen Blute. Pflitgers Archiv. 7, 274. 1873.

15. Fủrstenberg, Diẹ Fettgeschwälste und ihre Metamorphosen. Magazin f. Tierheilk. 17, 1. 1851.

16. Gabriel, S., Chemische Untersuchungen über die Mineralstoffe der Knochen und Zähne. Zeitschr. f. physiol. Chemie. 18, 257. 1893. 
17. Gascard, Analyse des concrétions sous-coutanées. Journ. d. pharm. et de chim. (6)。 12, 262, 1900.

18. Gerlach, L., Über die Bestimmung der Minerale des Blntserums dureh direkte Fallung. Ber. đ. K. sächs. Gesellsch. d. Wissensch, zu Leipzig. 1872. 349.

19. Grandis und Mainini, Sur nne réaction colorée qui parmet de révéler des sels de calcium deposés dans les tissus organiques. Archives ital. de Biol. 1900. Atti d. R. Accademie dei Lincei. (5). 9. Sem. I. 280. 1900.

20. Harley, V., Analyse de concrétions provenant d'une tumeur sous coutanée. Journ. de pharm. et de chim. (6). 18, 9. 1903.

21. Hlava, J., Zur Ätiologie der Lungenverkalkung. Wiener med. Blätter. 1882. 1100.

22. Hofmeister, F., Zur Lehre von der Wirkung der Salze. 6. Mitt. Archiv f. exper. Path. u. Pharm. 28, 226. 1891.

23. Huebschmann, V., Histologie der Kalkmetastase. Zentralbl. f. allgem. Pathol. u. pathol. Anat. 19, 737. 1908.

24. Jaeckle, H., Über die Zusammensetzung des menschlichen Fettes. Zeitschr. f. physiol. Chemie. 36, 83. 1902.

25. Kischenski, D., Über Kalkablagerungen in den Lungen und dem Magen. Autorreferat. Zentralbl. f. allg. Path, u. path. Anat. 12, 674. 1901.

26. Klotz, O., Studies upon Calcareous Degeneration. Journ. of Exp. Medicine. 7, 613. 1905.

27. Kockel, Über die Kalkinkrustation des Lungengewebes. Deutsches Archiv f. klin. Med. 64, 332. 1899.

28. Kóssa, J. v., Über die im Organismus künstlich erzeugbaren Verkalkungen. Zieglers Beiträge 29, 163. 1901.

29. Kühne, W., Physiol. Chemie. 184. 1868.

30. Küttner, Ein Fall von Kalkmetastase. Virehows Arch. 55, 521. 1872.

31. Langerhans, P. V., Über multiple Fettgewebsnekrose. Virchows Arch. 122, 256. 1890.

32. Lévy, E., Metastases calcaires classiques révélant une maladie osseuse chez le lapin. Arbeiten a. d. Geb. d. pathol. Anat. etc. Festschr. f. Baumgarten. 1908. 555.

33. Maly und Donath, Beiträge zur Chemie der Knochen. Journ. f. prakt. Chemie. 7, 43. 1873.

34. Nunakawa, K., Über Verkalkung der Pachymeninx bei Usura cranii. Virchows Arch. 198, 271. 1909.

35. Pauli, W., und H. Handowsky, Salzionenverbindungen mit amphoterem Eiweiss. Hof m e isters Beiträge 11, 415. 1908.

36. Pauli, W., und M. Samec, Löslichkeitsbeeinflussung von Elektrolyten durch Eiweisskörper. Biochem. Zeitschr. 17, 285. 1909.

37. Pfaundler, M., Utber die Elemente der Gewebsverkalkung und ibre Beziehung zur Rachitisfrage. Jahrb. f. Kinderheilk. 40. Ergänzungsheft. 123. 1903.

38. Přibram, R., Eine neue Methode zur Bestimmung des Kalks und der Phosphorsäure im Blutserum. Berichte d. K. sächs. Gesellsch. d. Wiss. 279. 1871.

39. Recklinghausen, F. v., Handb. d. allg. Pathol. 174 u. 389. Stuttgart 1893.

40. Rindfleis ch, E., Lehrbuch d. pathol. Gewebelehre. 3. Aufl. 37. Leipzig 1873.

41. Roth, M., Uber Metastasen von Kalk, Fett und Koblenstaub. Korrespondenzbl. d. Schweiz. Ärzte. 14, 226. 1884.

42. Schläpfer, F., Einige Beobachtungen über die Magendrüsen des Menschen. Vir ch ow s Arehiv. 7, 161. 1854.

43. Schuje nin of f, S., Zur Frage der Kalkablagerung im quergestreiften Muskel. Zeitschr. f. Heilk. 13, 79. 1897.

44. Schwarz, L., Zur Theorie der Saurebildung in der Magenschleimhaut. Hofmeisters Beitr. 5, 56. 1904.

45. Spiro, K., Über physik, u. physiol. Selektion. Habilitationsschr. Strassburg 1897.

46. Stade, F., Über Lungenverkalkung. I.-D. Kiel 1900.

47. Tillmanns, H., Deutsche Zeitschr. f. Chir. 7, 538. 1877. 
48. Virehow, R., Kalkmetastasen. Virchows Archiv. 8, 108.1855.

48a. Dersel be, Kalkmetastasen. Ebenda. 9, 618. 1856.

49. Voit, Fr., Beiträge zur Frage der Sekretion und Resorption im Dünndarm. Zeitschr. f. Biol. 29, 378, 1893.

50. Voit, C. v., Hermanns Eandb. d. Phys. 6, 371. 1881.

51. Wells, G., Pathological Calcifications. Journ. of. med. Research. 14, 491. 1905/6.

52. Werra, v., Über die Folgen des vorübergehenden und dauernden Verschlnsses der Nierenarterie. Virchows Archiv, 88, 205. 1882.

53. Wildt, E., Zusammensetzung der Knochen des Kaninchens in versehiedenen Altersstufen. Land wirtschaftl. Versuchsstationen, 15, 404. 1872.

Bei den pathologischen Verkalkungsvorgängen kommen wie bei der Knochenbildung als Mineralbestandteile wesentlich Calcium, Magnesium, Phosphorsäure und Kohlensäure in Betracht, da sie in den verkalkten Geweben zusammen über $95 \%$ der anorganischen Substanz ausmachen. Der Gehalt an Eisen, Chlor, Fluor, Natrium und Kalium tritt dagegen sehr zurück. Für das Verständnis der Verkalkungsvorgänge ist es daher vor allem notwendig die Bedingungen zu kennen, unter denen Phosphate und Carbonate der Erdalkalien dem Ort der Ablagerung zugeführt werden.

\section{I. Über den Lösungszustand der Erdalkalien im Blut.}

Da neugeborene Tiere nur einen verhältnismässig geringen Vorrat an Erdalkalien mitbringen, so muss der Hauptanteil der im ausgewachsenen Tier vorfindlichen Menge aus der Nahrung stammen, somit seinen Weg durch die Blutbahn genommen haben. Dieser Transport bereitet dem Verständnis insofern Schwierigkeiten als er in einfach wässeriger Lösung anscheinend unter Bedingungen erfolgt, die sonst die Abscheidung von unlöslichen Phos. phaten zur Folge haben.

Eine Berechnung auf Grund der vorliegenden Analysen $(1,28)$ ergibt, dass das Serum des Säugetierbluts $0,0067-0,0114 \% \quad \mathrm{PO}_{4}$ in anorganischer Form, und daneben soviel Calcium $(0,0079-0,150 \%)$ enthält, dass, wenn sämtliche anorganische Phosphorsäure damit zu sekundärem Phosphat $(0,0096$ bis $0,0163 \%$ des Blutserums) oder zu tertiärem Salz $(0,01093-0,0186 \%)$ zu. sammentritt, immer noch ein Kalküberschuss bleibt. Es fragt sich nun, ob unter diesen Verhältnissen Kalk und Phosphorsäure im Blutplasma neben einander in einfacher Lösung bestehen können.

Bringt man sehr verdünnte (z. B. $\left.{ }^{n} / 50\right)$ Iössungen von sekundärem Natriumphosphat und von Calciumchlorid in äquivalenten Mengen unter Zusatz von Wasser zusammen, so beobachtet man die erste Trübung (bedingt zunächst durch Bildung von $\mathrm{CaHPO}_{4}$ ) bei einem Gehalt der Lösung von $0,020 \%$ 
$\mathrm{CaHPO}_{4}$, was der vor langer Zeit von Birnbaum, Dusart und Pelouze u. a. ermittelten Löslichkeit des sekundären Caleiumphosphats von 0,0135 bis $0,028 \%$ entspricht. Mischt man hingegen die Lösungen unter Anwendung eines kleinen Überschusses von Calciumchlorid bei alkalischer Reaktion ich nahm 2 Volume der $\mathrm{n} / 50$-Chlorealciumlösung auf 1 Volum $\mathrm{n} / 50$-Natriumphosphatlösung, dazu die nötige Menge Wasser und setzte zu $10 \mathrm{ccm}$ des Gemenges $0,1 \mathrm{ccm} 10 \%$ ige Sodalösung, was dann einem Gehalt von $0,1 \%$ $\mathrm{Na}_{2} \mathrm{CO}_{3}$ entsprach -, so erfolgt die Abscheidung von tertiärem Kalkphosphat bereits bei einem Gehalt von $0,0078 \%$. (Nach Völker ${ }^{1}$ ) löst sich frischgefälltes tertiäres Calciumphosphat zu $0,0079 \%$ in reinem Wasser, nach Maly und Donath (33) gar nur zu $0,00236 \%$ ).

Unter der Annahme, dass die in Blutserum vorhandene anorganische Phosphorsäure sich mit dem überschüssig vorhandenen Calcium zu sekundärem Phosphat verbindet, könnte sonach dieses eben noch gelöst bleiben. Bei Anwesenheit von soviel normalem Alkalicarbonat, als das arterielle Blut enthält, müsste es jedoch zur Bildung von tertiärem Kalkphosphat kommen, dessen Löslichkeit etwas geringer ist, als dem oben berechneten Minimalgehalt des Blutserums $(0,01093-0,0186 \%)$ entspricht.

Es ist daher zu erwarten, dass schon normalerweise im Blutplasma Einrichtungen gegeben sind, welche der Abscheidung des Tricalciumphosphats entgegenwirken und so eine Aufnahme von gelöstem Kalksalz und Alkaliphosphat ins Blut über die Löslichkeitsgrenze des tertiären Phosphats hinaus ermöglichen, ohne dass es zu Niederschlagsbildung kommt. $\left.{ }^{2}\right)$ Für jene pathologischen Fälle, wo ein erheblicher Transport von Knochensalzen durch das Blut stattfindet, wie bei den sogenannten Kalkmetastasen, ist eine solche Annahme besonders schwer zu entbehren.

Behufs Erklärung der Tatsache, dass es nicht schon unter normalen Verhältnissen öfter zur Abscheidung von Kalkphosphat kommt, könute in erster Reihe an die anorganischen Salze des Blutes gedacht werden, da bekannt ist, dass Neutralsalze die Ausfällung von Di- und Tricalciumphosphat erschweren. Erst vor kurzem hat H. Aron (2) auf einen solchen Einfluss der Chloride hingewiesen. Doch ist nach meinen Erfahrungen bei einer so verdünnten Salzlösung, wie sie im Blute vorliegt, der Einfluss nicht merklich. Wenigstens fand ich bei obiger Versuchsanordnung in einer physiologischen Kochsalzlösung $(0,9 \%)$ die Löslichkeitsgrenze für frischgefälltes Kalkphosphat nicht anders als in destilliertem Wasser.

1) Jahresber. f. Chemie 1862, 131.

2) So bemerkt Fr. Vait (49) in seiner Arbeit über Kalkresorption "Unter allen Umständen wird er (i. e. der Kalk) wieder ausgefällt bei Berührung mit dem alkalischen dinatriumphosphathaltigen Serum, weshalb ein Übergehen desselben als anorganisches Salz in den zirkulierenden Säftestrom kaum denkbar ist". 
Hingegen ist die von namhaften Physiologen und Pathologen $(50,3)$ bevorzugte Vorstellung, wonach das Calcium im Blutplasma mit Eiweiss oder anderen organischen Substanzen in einer besonderen Form verbunden und so vor Ausfällung geschützt ist, in gewissem Sinn begründet.

Diese Vorstellung geht auf $\mathrm{Kühne} \mathrm{(29)} \mathrm{zurück,} \mathrm{der} \mathrm{seinerzeit} \mathrm{angab:}$ „Das Serum enthält etwas phosphorsauren Kalk $\left(3 \mathrm{CaO} . \mathrm{PO}_{\tilde{\nu}}\right)$, der sich beim Koagulieren des Eiweisses mit diesem ausscheidet, und füglich mit diesem in Verbindung existieren muss, weil er ohne dies im alkalischen Serum nicht löslich sein konnte." Fokker (14) hat dann die Annahme eines "Kalkalbuminats" im Blute durch künstliche Darstellung eines solchen und qualitative Reaktionen za stützen gesucht.

Dieser Vorstellungsweise gegenüber, ob man nun dabei an ein Kalkalbuminat, oder eine lösliche Kalkphosphateiweiss-, oder eine andere organische Verbindung des Kalks denkt, muss geltend gemacht werden, dass sie die Nichtfällbarkeit des Calciums nur erklären könnte, wenn es darin in organisch gebundener oder sonst in nichtionisierter Form vorhanden wäre. Wie jedoch bereits vor langer Zeit von R. Pribra m (38), L. Gerlach und E. Drechsel (18) nachgewiesen wurde, ist das Calcium des Blutserums durch Am. moniumoxalat ganz fällbar, was eine „organische" Bindung ausschliesst. In der Tat liegt für die Annahme eines nicht ionisierten Kalkalbuminats oder einer solchen Eiweisskalkphosphatverbindung kein Beweis vor, denn analoge Eiweissverbindungen z. B. Kalialbuminat, Globulinsalzverbindungen etc. enthalten die anorganischen Bestandteile, soweit Reaktionen einen Schluss gestatten, in ionisierter Form ${ }^{1}$ ).

Da indes Salzionen mit Eiweiss zu „Adsorptionsverbindungen" zusammentreten (35), so ist die Annahme einer echten chemischen Bindung zwischen Kalk und Eiweisskörpern des Serums gar nicht notwendig. Der Kolloidgehalt des Plasmas genügt, wie G. Wells (51) neuerdings wieder betont hat, zur Erklärung. Wie andere kolloide Lösungen die Ausfällung von kolloiden Niederschlägen erschweren oder unmöglich machen, so ist Ähnliches auch von dem 7-8\% Eiweiss enthaltenden Blutplasma zu erwarten.

Pauli und Samec (36) haben in der Tat die lösende Wirkung von Serum gegenüber Calciumphosphat und Calciumcarbonat nachgewiesen und sogar quantitativ bestimmt.

Sehr leicht lässt sich diese ausfällungshemmende Wirkung mit unverdünntem Blutserum (ich benutzte solches vom Pferde) zeigen.

Versetzt man gleiche Mengen Serum mit äquivalenten Mengen von Calciumchlorid und Dinatriumphosphat - ich benutzte ${ }_{5}^{5}$-Lösungen - so kommt

1) Dass das Eiweiss im Blutplasma gleichzeitig mit Chlorionen und mit Calcium Ionen in Verbindung steht, ist gat denkbar. Doch ist die Verteilung von Säuren und Basen in einem so komplizierten Gemenge, wie es das Blutplasma ist, bekanntlieh nur sehr unvollkommen $\mathrm{zu}$ beurtei]en. 
es wohl zu Opaleszenzen, aber selbst bei beträchtlichem Zusatz über die Löslichkeitsgrenze der sekundären Calciumphosphate hinaus nicht zu Niederschlägen, während in mit Wasser ausgeführten Parallelversuchen sich rasch absetzende flockig-gelatinöse Niederschläge auftreten. Noch auffälliger ist der Unterschied bei nachträglichem Alkalizusatz, wo es zur Ausfällung des tertiären Calciumphosphats kommen sollte; zwar weisen die auftretenden Opaleszenzen darauf hin, dass es zu einer Reaktion unter Bildung von Kalkphosphat kommt, allein flockige Niederschlagsbildung bleibt bis zu einem Gehalt von $0,15 \% \mathrm{Ca}_{3}\left(\mathrm{PO}_{4}\right)_{2}$, also dem Zehnfachen des Normalgehalts des Blutplasmas, stundenlang aus.

Diese Suspensionswirkung des Serums lässt sich auch anderen kolloidal ausfallenden Salzen gegenüber nachweisen. So wird auch die Ausfällung des Kalks durch Natriumcarbonat Kontrollproben mit Wasser gegenüber zunächst sehr merklich verzögert; da jedoch nach einiger Zeit das Caleiumcarbonat krystallinisch wird, so gleicht sich später die Differenz wieder aus. Sehr auffällig ist die Fällungshemmung gegenüber Kalkseifen. Bringt man abgemessene Mengen Seifenlösung und Chlorcalcium einerseits zu physiologischer Kochsalzlösung, andererseits zu Blutserum, so bleibt der Niederschlag im Serum noch bei Konzentrationen stundenlang aus, bei denen er in der Kochsalzlösung bereits dicke, flockige Beschaffenheit angenommen hat ${ }^{1}$ ).

Eine ähnliche hemmende Wirkung äussert das Blutserum gegenüber der Ausfällung des amorphen Magnesiumhydrophosphats, nicht aber gegenüber dem krystallinischen Tripelphosphat und Calciumfluorid.

Dass es sich nicht um eine spezifische Eiweisswirkung handelt, wird dadurch bewiesen, dass nach älteren gelegentlichen Beobachtungen ${ }^{2}$ ) und neuen Versuchen von Pauli und Samec (36) auch Leimlösung die Abscheidung von Kalkphosphat sehr merklich hemmt ${ }^{3}$ ).

Nach dem Gesagten ist zu erwarten, dass bei Verdünnung des Blutserums infolge der Abnahme der kolloidalen Beschaffenheit seine tällungshemmende Wirkung abnehmen wird. Das ist in der Tat der Fall. Bei Verdünnung des Blutserums unter einen Eiweissgehalt von $2 \%$ wird sie merklich schwächer. Blutserum, das so verdünnt ist, dass es nur $0,1 \% \mathrm{Ei}$ weiss enthält, lässt gegenüber Wasser keinen Unterschied mehr erkennen.

Danach ist auch die Beobachtung von $\mathrm{K} u ̈ h n e$ und anderen, dass beim Auskoagulieren des Eiweisses Tricalciumphosphat mitfällt, einfach physikalisch verständlich. Die Abscheidung des die Suspension vermittelnden Kolloids bedingt die Abscheidung des suspendierten Phosphats. Von all-

1) Der Kalkgehalt des Blutplasmas ist sonach kein Hindernis für die Aufnahme von Seifen ins Blut, wie denn die Anwesenheit von Seifen im Blut längst erwiesen ist.

2) Vgl. Wöhler, Ann. d. Chemie n. Pharm. 98, 143. (1856).

3) Dass aber in dieser Richtung nicht alle Kolloide gleich wirksam sind, ist vorauszasehen. Ieh habe z. B. Saponin und Stärkelösung obne Wirkung gefunden. 
gemeinem Interesse ist, dass die kolloide Beschaffenheit des Blutplasmas, bezw. sein hoher Eiweissgehalt, den Transport von in Wasser an sich unlöslichen Stoffen, Phosphaten, Kalkseifen und Lipoiden in kolloid gelöster Form ermöglicht. Ob dabei bestimmten Eiweisskörpern des Blutes eine besondere Aufgabe zufällt, bleibt noch zu untersuchen.

\section{II. Über Knochenresorption.}

Der normale Knochen unterliegt wie andere Gewebe einer steten Erneuerung. Ansatz und Abgabe halten sich beim Erwachsenen das Gleichgewicht. Wie aus Erfahrungen an hungernden und auf kalkarme Nahrung gesetzten Tieren hervorgeht, betrifft die Abgabe auch den anorganischen, vorwiegend aus Kalkphosphat bestehenden Anteil. Noch augenfälliger geht die Angreifbarkeit aus dem Schwund der Knochensubstanz unter dem Einfluss von Geschwülsten, Aneurysmen, Granulationen hervor. Die Resorption von neugebildeter Knochensubstanz nach Implantation von Periost in grosse Gefässe (8), die Resorption von durch Arterienunterbindung erzeugten Kalkablagerungen in der Niere (52), von Verkalkungen in Muskelnarben (43) sind weitere Beispiele. Dass dabei vitale Vorgänge in dem der Resorption unterliegenden Gewebe nicht mitzuspielen brauchen, geht aus der bekannten Tatsache hervor, dass auch toter Knochen und Elfeubein von Granulationen arrodiert wird.

Bei diesem Vorgang hat in erster Reihe die Angreifbarkeit des anscheinend so widerstandsfähigen anorganischen Anteils die Aufmerksamkeit auf sich gezogen. Während eine Anzahl von Autoren die Arrosion nur durch besondere vitale Leistungen des arrodierenden Protoplasmas erklären zu können glaubt, halten andere (z. B. Rindfleis cb) eine rein chemische Erklärung - Auflösung durch vom Protoplasma gebildete Säure - für ausreichend. Dass die zweite Frklärungsweise als die einfachere und der Prüfung zugänglichere den Vorzug verdient, dürfte allgemein empfunden werden.

Wenn Granulationen, Geschwulstpartien, Osteoklasten usw., die der Knochensubstanz anliegen, deren Lösung bewirken, so besagt das im Sinne der zweiten Vorstellungsweise, dass die lebenden Zellen an der Berührungsfläche ein Lösungsmittel abgeben, und zwar kann da, soweit man sieht, nur eine Säure in Frage kommen. Da das Leben des Protoplasmas sich mit der Anwesenheit freier Mineralsäuren in demselbeu nicht verträgt, so hat man an Milchsäure und Kohlensäure gedacht. Da nun die Kohlensäure im Protoplasma" stetig gebildet und von ihm als unverwertbares Abfallprodukt nach aussen abgegeben wird, kommt sie dabei in erster Reihe in Betracht, und wenn sich nachweisen lässt, dass ihre Wirkung zur Erklärung der Knochen- 
lösung quantitativ genügt, dürfte das Suchen nach anderen im gleichen Sinne wirksamen Lösungsmitteln überflüssig sein.

Dass im Wasser gelöste Kohlensäure auf Knochensubstanz lösend einwirkt, ist längst bekannt. Maly und Donath (33) bestimmien den Gewichtsverlust einer etwa $2 \mathrm{~g}$ wiegenden geschliffenen Knochenplatte aus dem Ochsenfemur in kohlensäurehaltigem Wasser bei achttägiger Einwirkung zu etwa $2 \%$, während Kochsalzlösung nicht stärker lösend wirkte als Wasser allein, sekundäres Natriumphosphat und Natriumbydrocarbonat sogar noch weniger. Tillmanns (47) setzte Elfenbeinstäbchen bei $37-38^{0}$ einem langsamen Strom von kohlensäurehaltiger Kalkphosphatlösung aus, was bei mehrwöchentlicher Daner zu ausgesprochener Arrosion und einem merklichen Gewichtsverlust führte. Versuche, die Tanaka') über meinen Wunsch anstellte, haben genauere Daten über die lösende Wirkung kohlensäurehaltiger Flüssigkeiten im Verhältnis zur dargebotenen Knochenfläche ergeben. Er leitete einen langsamen Strom von Wasser, von $0,9 \%$ iger Kochsalzlösung und von Rinderblutserum, sämtlich mit Kohlensäure gesättigt und toluolhaltig, mehrere Tage über ge. schliffene und gewogene Elfenbein,, Knochen- und Zahnplatten bei $37^{\circ}$ und bestimmte die Gewichtsabnahme pro Tag und $10 \mathrm{qcm}$ Oberfläche. Sie ergab sich für:

$\begin{array}{lrrc} & \text { Elfenbein: } & \text { Knoehen: } & \text { Zahnsubstanz: } \\ \text { in Wasser zu } & 0,0133 \mathrm{~g} & 0,0139 \mathrm{~g} & 0,0082 \mathrm{~g} \\ \text { in Kochsalzlösung zu } 0,0203 " & 0,0167 " & 0,0106 " \\ \text { in Rinderserum zu } & 0,0103 " & 0,0028 " & 0,0014 "\end{array}$

Die lösende Wirkung kohlensäurereicher Flüssigkeiten auf Knochen. substanz ist danach, falls, wie dies im Körper verwirklicht ist, eine ausreichend grosse Berührungsfläche vorliegt, recht erheblich und dürfte reichlich genügen die bei pathologischen Prozessen beobachtete Arrosion zu erklären, zumal da es sich hier um sehr lang dauernde Einwirkungen handelt.

Dabei ist die lösende Wirkung einer kohlensäuregesättigten Kochsalzlösung durchweg am grössten, jene des gleichgesättigten Serums am geringsten. Das Blut schützt anscheinend die Knochen vor der Arrosion durch die Kohlensäure, was sich sehr einfach daraus erklärt, dass das Blut, wie das Serum, bereits gelöstes Kalkphosphat enthält, daher ein geringeres Lösungsvermögen dafür besitzt. Zugleich ist daraus zu entnehmen, dass die arrodierende Wirkung der Gewebsflüssigkeiten bei einem geringeren Gehalt an Kalksalzen (z. B. bei Hunger und bei ungenügender Kalkzufuhr) zunehmen muss.

Die oben beobachtete Gewichtsabnahme der Knochenplättchen berubt, wie wir uns überzeugen konnten, wesentlich nur auf Lösung der Kalksalze. Die mikroskopische Untersuchung unter Anwendung der Schwefelsäurereaktion

1) Die Einzelheiten wird Herr Tanaka an anderer Stelle mitteilen. Über einige Ergebnisse der von Herrn Tanaka in meinem Laboratorium ausgeführten Versuche habe ich am 25. Juni $1909 \mathrm{im}$ Strassburger naturwissenschaftlich-medizinischen Verein berichtet. 
ergab am durehsichtigen Rande der Plättchen bis zu einer gewissen Tiefe das Fehlen von Kalk, während die organische Grundsubstanz anscheinend intakt war. Es liegt hier somit in der Tat eine Halisterese vor. Dass die Auflösung der organischen Grundsubstanz mit jener der Phosphate gleichen Schritt geht, wie Flesch (13) und Tillmanns nach Versuchen in vitro angeben, trifft somit unter den von uns eingehaltenen Bedingungen nicht zu.

Da nach den Erfahrungen von Maly nnd Donath Natriumhydrocarbonat keine lösende Wirkung ausübt, so kommt im Organismus für die Lösung der Knochensubstanz neben dem Wasser an sich, das nur etwa $0,003 \%$ aufzunehmen vermag, nur freie Kohlensäure in Betracht. Es ist danach zu erwarten, dass Gewebe mit lebhaftem Stoffwechsel bezw. reichlicher Kohlensäurebildung am ehesten eine lösende Wirkung entfalten dürften. Dies trifft für Granulationsgewebe und wuchernde Geschwülste besonders zu. Dass aber auch andere Gewebe ein gewisses Lösungsvermögen besitzen, geht aus Versuchen von Tanak a bervor, bei denen getrocknete und gewogene Elfenbeinnadeln Kaninchen aseptisch in Leber, Milz, Niere, Muskel und Unterhautbindegewebe eingeführt wurden. Die nach 19 Tagen herausgenommenen Nadeln zeigten in allen Fällen eine gewisse Gewichtsabnahme, die auf die Fläche bezogen bei der Milz und Niere am grössten, beim Muskel und dem Unterhautbindegewebe am geringsten war.

Die Bedeutung der Kohlensäure für den Lösungsvorgang erklärt ferner die begünstigende Wirkung der Kompression bei der Knochenarrosion. Nur wenn das kohlensäureproduzierende Gewebe unmittelbar dem Knochen anliegt, kann die lösende Wirkung voll zur Geltung kommen. Eine Zwischenschicht von blutdurchströmtem Gewebe müsste durch Koblensäureentziehung hindernd wirken. Dass der mechanische Druck an sich bei dieser "Kompressionswirkung" keine Rolle spielt, ist schon von Till man n s betont worden.

Es leuchtet fermer ein, dass die Kohlensäureproduktion pflanzlicher Parasiten, falls sie direkt Knochengewebe trifft, wie dies bei den in den Zahnkanälchen bei Karies vegetierenden Bakterien der Fall ist, ebeufalls zu Arrosion führen muss. Die Annahme einer spezifischen Säurebildung ist da um so weniger nötig, als auch die Lösung von Calciumphosphat und Calciumcarbonat durch Pflanzenwurzeln nach Czapek (9) auf. Kohlensäureeinwirkung zurückzuführen ist.

\section{III. Über den Verkalkungsvorgang. ${ }^{1}$ )}

Von ätiologischen Gesichtspunkten ausgehend unterscheidet man zwei Hauptformen der pathologischen Verkalkung, die dystrophische und die metastatische.

1) Von den Kalkkonkrementen in Se- und Exkreten ist hier abgesehen, da deren Bildung von ganz anderen Bedingungen abhängt als die Gewebsverkalkung. 
Die dystrophische Verkalkung betrifft einzelne Gewebe im Zustande der Unterernährung, von der einfachen Altersveränderung an bis zur schweren Degeneration, ohne nachweisbare Beziehung zu einer Veränderung des Skeletts. Die metastatische Verkalkung ist fast nur im Anschluss an ausgebreitete Knochenveränderungen beobachtet und lokalisiert sich in anscheinend vorher ganz gesundem Gewebe und zwar zumeist in der Lunge, der Niere, der Magenschleimhaut und der Gefässwand. Während es sich im ersteren Falle um eine Ablagerung von dem Organismus zugeführten Kalksalzen handelt, stammen die Kalksalze der Kalkmetastasen nach Virchows Vorstellung aus den erkrankten Knochen.

In chemischer Richtung ergibt sich eine ganz andere Gruppierung. Danach kann die Verkalkung bestehen in der Ablagerung von Phosphaten und Carbonaten der alkalischen Erden einerseits oder aber von Fettsäureverbindungen derselben (Kalk- und Magnesiaseifen) ${ }^{1}$ ) andererseits.

Die Verkalkungen der ersten Art sind sehr verbreitet. Sie nähern sich, wie G. Wells (51) gelehrt hat, der Zusammensetzung nach der Knochenerde.

Die Bildung von Kalkseifen ist viel weniger häufig in grösserem Umfang beobachtet. Sie erfolgt naturgemäss nur in fettreichem Gewebe und zwar stets von Verkalkung des Knochentypus begleitet. Dabei treten die Seifen der Erdalkalien gegen die Phosphate quantitativ sehr zurück. Der höchste Gehalt daran $(29,5 \%)$ ist von Jaeckle (24) in einem verkalkenden Lipom gefunden worden.

\section{A. Die dystrophische Verkalkung.}

Zur Erklärung der Kalkablagerung bei der dystrophischen Form der Verkalkung sind verschiedene Momente herangezogen worden, in erster Reihe das Auftreten von Stoffen mit besonderer Aufnahmsfähigkeit für Kalk.

Dieser Fall ist in sehr einleuchtender Weise verwirklicht bei der Verkalkung, die im Gefolge der Fettgewebsnekrose eintritt. Hier kommt es durch Einwirkung der Pankreaslipase zum Auftreten von Fettsäuren und ihren Alkalisalzen, die nun, soweit sie nicht resorbiert werden, als „Kalkfänger" aus dem Blute Kalk aufnehmen. Dieser schon von Langerhans (31) klar erkannte Vorgang kann sich bei dem geringen Kalkgehalt des Blutes nur langsam vollziehen. Klotz (26) hat ihn in der Art experimentell nachzuahmen versucht, dass er Celloidinkapseln, die Natriumstearat und Na-

1) Die ersten genaueren qualitativen und quantitativen Untersuchungen uber das Vorkommen von Kalkseifen stammen ron Fürstenberg (15). Er fand sie in verfettenden Lipomen. Ihr Auftreten bei Fettnekrose ist zuerst von Langerhans und Salkowski (3I) festgestellt worden. 
triumpalmitat enthielten, in die Peritonealhöhle eines Kaninchens brachte und nach 11 Tagen wieder entfernte. In beiden Fällen ergab sich ein erheblicher Kalkgehalt $(3,8$ und 4,0\%) in dem Kapselinhalt.

Es ist anzunehmen, dass auch bei Verkalkung von Lipomen die Fettspaltung der Bildung der Kalkseifen vorangeht, wenn auch hier das Auftreten eines fettspaltenden Fermentes nicht direkt erwieseu ist.

Wie leicht Fett unter günstigen Bedingungen verkalkt, geht aus dem folgenden gemeinsam mit Dr. Tanaka ausgeführten Versuche hervor. Verschiedene Organe von Kaninchen (Leber, Muskel u. a.) wurden nebst einem Stück Netz in eine flache Schale gelegt, durch die bei $37^{\circ}$ ein langsamer Strom einer Lösung von saurem Calciumphosphat und Calciumcarbonat floss, die durch Suspendieren ron Calciumphosphat in Wasser und Durchleiten von Kohlensäure erhalten war. Die meisten eingebrachten Organe zeigten trotz mehrwöchentlicher Dauer des Versuchs im Innern keine Kalkablagerungen. Nur das Fett des Netzes wurde in dieser Zeit starr, fühlte sich sandig an und enthielt reichlich Kalk. Ein gleicher Versuch mit frischem Schweinefett führte, wenn auch etwas später zum gleichen Resultat. Ebenso geht aus den weiter unten angeführten Injektionsversuchen von Tanaka hervor, dass Fettgewebe, das im Tierkörper mit der Lösung eines Kalksalzes in Berührung steht, der Verkalkung unter Kalkseifenbildung unterliegt.

Weniger leicht verständlich ist das Zustandekommen der bei weitem häufgeren Form von dystrophischer Verkalkung, die durch Ablagerung von Erdalkali-Phosphat und -Carbonat zustande kommt. Um hier die Lokalisation in einem bestimmten anatomischen Substrat zu erklären, hat man verschiedene Momente herangezogen.

So hat man daran gedacht, dass in den unterernährten Geweben aus darin enthaltenen Phosphatiden - Nucleoproteiden und phosphorhaltigen Lipoiden - bei der Nekrobiose Phosphorsäure abgespalten wird, welche dann den mit dem Blut zugeführten Kalk niederschlägt. Diese Vorstellung scbien eine Stütze zu finden in einer Mitteilung von Grandis und Mainini (19), wonach im verknöchernden Gewebe anorganische Phosphorsäure aus organischgebundener entsteht und dann den Kalk fixiert. Die quantitative Überlegung ergibt jedoch die völlige Unzulänglichkeit dieser Anschauungsweise. Schlägt man den Phosphorgehalt der der Verkalkung unterliegenden Organe hochgegriffen zu $0,2-0,25 \%$ an, so könnte selbst durch Überführung des gesamten vorhandenen Phosphors in Kalkphosphat nur ein Gehalt daran von etwa 1-1,25\% zustande kommen, während verkalkte Gewebe, soweit sie makroskopisch als solche erkennbar sind, viel mehr, bis zu $60 \%$ enthalten. Der ursprüngliche Phosphorgehalt könnte sonach vielleicht zur Erklärung einer mikroskopisch eben erkennbaren Kalkinfiltration ausreichen; was darüber geht, bedürfte doch einer anderen Erklärung. 
Überdies zeigt die Erfahrung, dass keineswegs die an phosphorhaltigen Stoffen (Lipoiden und Nuclein) reichsten Gewebe besonders zur Verkalkung neigen, wie schon das Verhalten des am meisten. der Verkalkung ausgesetzten Gewebes, des Knorpels, lehrt. Endlich hat Wells (51) Stücke von nucleinreichen Geweben (Milz, Thymus) nach vorgängigem Sterilisieren in die Bauchhöhle von Kaninchen eingebracht und nach Wochen im Gegensatz zu ebenso behandeltem Knorpel unverkalkt gefunden.

Andererseits ist daran gedacht worden, dass der Phosphatverkalkung stets die Bildung von Kalkseifen vorangeht. Auf Grund bistologischer Untersuchung ist diese Meinung jüngster Zeit besonders lebhaft von Klotz vertreten worden. Er fand Kalkseifen durch Färbung in allen verkalkenden Geweben, während er sie bei alten Verkalkungen vermisste. Der Verkalkungsvorgang in nekrobiotischem Gewebe würde sich nach seiner Vorstellung in folgenden Stadien abspielen: Fettinfiltration, Verseifung des Fettes, Bildung von Kalkseifen, Umsetzung der Kalkseifen mit den Alkaliphosphaten der Lymphe unter Rückbildung von Alkaliseifen, die nun neuerdings Kalk aufnehmen und so, man könnte sagen katalytisch, immer wieder zu Ablagerung von Kalkphosphat führen.

Dieser Vorstellungsweise steht die von $\mathrm{W}$ ells sichergestellte Tatsache entgegen, dass in Verkalkungen, auch wo sie in "fettig degeneriertem" Gewebe z. B. tuberkulösen Lymphdrüsen, auftreten, in den frühen Stadien höchstens Spuren von Kalkseifen und auch sonst nur sehr geringe Mengen anderer Seifen oder freier Fettsäuren gefunden werden. Daș Auftreten kompakter Verkalkungen würde eine ausgiebige Fettinfiltration als regelmässiges Vorstadium voraussetzen, was mit den pathologischen Erfabrungen nicht in Einklang steht. Ich möchte hinzufügen, dass der Transport der Fette im Organismus zu und von den Ablagerungsstätten bei der Unlöslichkeit und Nichtdiffusibilität der Fette nur unter der Voraussetzung verständlich ist, dass sie vorübergehend eine Verseifung erfahren, und dass, falls die Alkaliseifen in obigem Sinne katalytisch zu Kalkseifenbildung führten, das Auftreten von Verkalkungen überaus häufig sein müsste. Übrigens sprechen die Erfahrungen über experimentelle Verkalkung (s. unten) nicht für diese Vorstellung. Bei Überschuss von Kalksalz erfolgt die Ablagerung von Kalkphosphat und von Kalkseifen je nach dem vorhandenen Substrat neben-, nicht nacheinander. Auch die rasche Bildung solcher Verkalkungen im Muskel und zumal in den Lymphspalten (in 24-48 Stunden) ist mit der Annahme einer vorausgehenden ,fettigen Degeneration" nicht in Einklang zu bringen. Einen prinzipiellen Gegensatz zwischen der Kalkablagerung im Knochen und der pathologischen Verkalkung auf Grund des Fehlens bezw. des Vorhandenseins der Kalkseifenbildung anzunehmen, wie dies Klotz tut, ist daher nicht notwendig. 
Weiter kann man behufs Erklärung der Kalkablagerung eine spezifische physikalisch-chemische Verwandtschaft der zur Verkalkung neigenden Gewebearten - Knorpel, elastisches Gewebe, Bindegewebe, hyalin, kolloid und anderweitig degeneriertes „Protoplasma“ - zu den Knochensalzen annehmen. Diese Vorstellung hat ihr Vorbild in der normalen Ossifikation.

Von diesem Gesichtspunkt aus hat Pfaundler (37) die Aufnahme von Kalk durch verschiedene tote Gewebe untersucht. Er brachte Stücke von Epiphysenknorpel, Muskeln, Nieren, Thymus in Chlorcalciumlösung und konnte an dieser bei mehrtägigem Verweilen eine erhebliche Abnahme an Calcium, dagegen keinen oder doch nur einen sehr geringen Chlorverlust nachweisen. Ein ganz ähnliches Verhalten zeigten Gelatineplatten. Ebenso konnte bei Durchspülung des lebenswarmen Tierkörpers mit Chlorcalcium eine Bindung von Calcium durch die Gewebe festgestellt werden. Pfaundler fasst diese Calciumbindung, die übrigens nie mit eigentlicher Verkalkung einherging, als die Folge einer elektiven Ionenadsorption auf, die er mit der von mir (22) und Linnemann, dann von Spiro (12) untersuchten Farbstoffadsorption durch Leimplatten in Parallele stellt. Die Annahme einer chemischen Kalkbindung erscheint ihm unbefriedigend, weil die Calciumaufnahme durch die Gewebe nicht in einfachem Verhältnis zu deren Menge steht, weil ferner Gelatineplatten den aufgenommenen Kalk an destilliertes Wasser wieder abgeben. Seine Auffassung der Kalkeinlagerung bei der Knochenverkalkung fasst er dahin zusammen, dass im Knorpel in einem bestimmten Stadium der Entwickelung ein Bestandteil auftritt, der eine spezifsche (ursprüuglich wohl mechanische) Affinität zu den Kalksalzen besitzt; ,die derart zum Kalksalzfänger umgewandelte Masse wird zunächst von gelösten Kalksalzmassen durchdrungen, die mit der organischen Grundlage in Verbindung treten und bei deren Abbau präzipitieren."

Nach Pfaundler kann eine ähnliche Auffassung auch auf die pathologiscbe Vorkalkung Anwendung finden. Es ist aber notwendig vorläufig im Auge zu behalten, dass von dieser Auffassungsweise nur jener Teil ex. perimentell gestützt ist, der sich auf die selektive Aufnahme von Calciumionen bezieht. Dass eine spezifische Affinität im lebenden Organismus bis zur Verkalkung führen kann, haben Versuche von G. Wells gezeigt. Ex brachte, wie oben erwähnt, Stücke verschiedener Gewebe, Knorpelsubstanz, Fettgewebe, Muskel, Thymus und Milz in die Bauchhöble von Kaninchen. Während die anderen Gewebe nur eine geringere oder stärkere Erweichung und Resorption erkennen liessen, war die Knorpelsubstanz bei längerem Verweilen stark verändert. Nach 14 Wochen war sie in eine besonders an der Peripherie von Kalkschuppen durchsetzte Masse umgewandelt. Der Kalkgehalt der eingebrachten Gewebstücke betrug in Milligrammen pro Gramm Gewebe: 
ursprünglich nach 4 Wochen 6 Wochen 8 Wochen 10 Wochen 12 Wochen 14 Wochen

$\begin{array}{lrrrrrrr}\text { Muskel } & \pm 0,4 & - & 4,7 & 6,4 & 11,3 & - & - \\ \text { Fett } & \text { Spur } & - & 1,0 & - & 3,3 & 4,7 & - \\ \text { Milz } & \pm 0,3 & - & 3,3 & - & 8,4 & - & - \\ \text { Thymus } & \text { Spur } & - & - & 8,7 & - & - & 12,0 \\ \text { Knorpel } & 3,3 & 15,5 & - & - & 124,6 & 162,0 & 154,0\end{array}$

Die chemische Untersuchung der verkalkten Knorpelmasse ergab einen Phosphorsäuregehalt, der sehr nahe dem des normalen Knochens entsprach.

$\mathrm{Da}$ in diesen Versuchen vom Knorpel neben Calcium auch Phosphorsäure aufgenommen wurde, müsste die von Pfaundler betonte Adsorptionstheorie auch auf diese ausgedehnt werden ${ }^{1}$ ).

Die Annahme elektiver, mechanischer oder chemischer Affinitäten für Calciumionen (eventuell auch für Phosphorsäureionen) in dem zur Verkalkung neigenden Gewebe erleichtert gewiss die Auffassung des ersten Schrittes zur Verkalkung, der Aufnahme der betreffenden Ionen, erklärt aber nicht die Präzipitation des Kalkphosphats und die stete Wiederholung der Aufnahme und der Präzipitation bis zur kompakten Verkalkung. Denn a priori ist nach Sättigung der betreffenden Affinitäten ein Stillstand der Aufnahme zu erwarten. Damit sich diese immer wiederholt, ist es notwendig, dass stets neue Affinitäten auftreten oder aber, dass die ursprünglich vorhandenen aber bereits gesättigten immer wieder frei werden.

In letzterer Richtung kommt in Betracht, dass der Gehalt der die Gewebe durchtränkenden Lymphe an Kohlensäure nicht konstant ist. Die Kalk. aufnahme könnte sich dann in folgender Weise vollziehen. Das Substrat sättigt sich zu einem Zeitpunkt, wo die Kohlensäure überwiegt, mit gelöstem Calciumphosphat und-carbonat und gibt in einem späteren Zeitpunkt, wenn die Lymphe kohlensäurearm geworden ist, an diese Kohlensäure ab, worauf die aufgenommenen Kalksalze ausfallen. Dadurch gewinnt das Substrat die Fähigkeit zurück, neuerdings gelöste Kalksalze bis zur Sättigung zu absorbieren; diese fallen bei einer neuerlichen Abnahme des Kohlensäureüberschusses wieder aus, und so fort. Bei einem bestimmten Grade der Imprägnation mit ausgefälltem Kalksalze müsste wegen der veränderten physikalischen Bedingungen die Aufnahme ein Ende finden. Dass in den Perioden des Kohlensäureüberschusses das vordem ausgefallene Kalksalz nicht sofort wieder in Lösung geht, erklärte sich aus der bekannten Erscheinung, dass ein durch Neutralisation erzeugter Niederschlag nur sehr langsam in der äquivalenten Säuremenge wieder in Lösung geht, wie denn überhaupt feste Körper und Suspensionen - wegen der relativ kleineren Oberfläche - weniger reaktions-

1) In der Tat geben zufolge einer Angabe von Bottazzi (6), Frommherz und Guggert an, dass die Rnorpelsubstanz auch für Natriumphosphat eine besondere Aafnahmsfahigkeit besitzt. Doch habe ieh die Quelle dieser Angabe nicht anffinden können. 
fähig sind als Lösungen. Es bedürfte sonach zur Lösung der gefällten Phosphate einer längeren Einwirkung des Kohlensäureüberschusses. Dass es zu einer solchen Resorption gerade in unterernährten Geweben minder leicht kommt, könnte daran liegen, dass die im Gefolge der Stoffwechselherabsetzung eingetretene verminderte Kohlensäurebildung der Kalkablagerung günstig ist, dass ferner die trägere Lymphströmung nicht wie in lebhaft funktionierenden Organen zum Ausschwemmen des ausfallenden Kalkniederschlags aus den Lymphräumen führt, und dass es so zur Verstopfung der Lymphwege und. damit zu einer weiceren Herabsetzung der Ernährung kommt, ein Verhalten, worauf v. Recklingbausen (39) binweist, indem er die relative Ruhe der das schwer lösliche Material heranführenden Flüssigkeit als eine Bedingung der Verkalkung hervorhebt.

Dass degenerative Vorgänge im Protoplasma zu einer Steigerung der Aufnahmefähigkeit für Kalksalze führen, ist durch die interessanten Versuche v. Kóssas (28) bewiesen. Beibringung von Jodoform per os erzengte bei Kaninchen Degeneration und Kalkinfiltration in der Leber. Bei gleichzeitiger subkutaner Kalkzufuhr trat die Kalklablagerung früher auf ${ }^{1}$ ).

(Im Gegensatz zu Pfaundler und v. Kossa glauben Pauli und Samec von der Annahme einer spezifischen Kalkbindung absehen zu können. Sie sind geneigt, als Ursache der Verkalkung zwei Prozesse anzunebmen: 1. Eindickung von tierischem Gewebe, 2. Abbau der Proteinstoffe in solchem wasserverarmten Körpermaterial. Diese Auffassung lässt sich mit den vorliegenden experimentellen und pathologischen Erfahrungen nur zu geringem Teil in Einklang bringen. Doch wird ein Urteil erst gestattet sein, wenu die von den Autoren in Aussicht gestellten weiteren Mitteilungen vorliegen.)

Von weiteren Erklärungeversuchen der dystrophischen Gewebsverkalkung ist noch die Vorstellung zu erwälnen, wonach die Kalkphosphatablagerung durch Bildung alkalisch' reagierender Stoffe bei der Nekrobiose eingeleitet oder begünstigt werden soll. In der Tat kann man sich denken, dass bei degenerativen Vorgängen Ammoniak oder ein ähnlicher basischer Körper frei wird, der einfach durch Säureentziehung das in der umspülenden Lymphe vorhandene, durch Kohlensäure in Lösung erhaltene Calcium zum Ausfallen bringt. Eine solche Vorstellung würde der oben dargelegten Auffassung (Kalkphosphatabscheidung infolge der Entziehung von Kohlensäure) entsprechen. Doch liegt zurzeit kein Beweis für das Vorkommen eines derartigen mit Alkalientbindung einhergehenden Prozesses vor.

Man hat endlich auch noch die Ansicht ausgesprochen, dass die

1) Die geringe Zahl der Versuche schliesst den Einfluss individueller Verschiedenheiten der Versuchstiere nicht aus. Es sei darum bemerkt, dass nach Tanakas und meinen zahlreichen Erfahrungen die intraperitoneale Injektion von Kalksalzen (s. u.), auch wenn sie zu ausgebreiteter Verkalkung führt, das Leberparenchym unberührt ]ässt. Das verleiht v. Kóssas Versuchen erböhte Beweiskraft. 
unterernährten Gewebe das ihnen zugeführte Eiweiss so vollständig ausnützen, dass der vom Eiweiss in Lösung gehaltene Kalk ausfällt. Darin liegt aber ein Widerspruch. Nach der Menge des aufgenommenen Kalks zu schliessen, müssten dann verkalkende Gewebe wenigstens im Beginn das Bild einer Eiweissüberernährung zeigen, und es müssten Gewebe mit leb. haftem Stoffwechsel und starkem Eiweissverbrauch besondets zu Verkalkung neigen, was beides nicbt zutrifft.

\section{B. Die Kalkmetastase.}

Fasst man nur jene Fälle als hierhergehörig auf, welche die von Virchow als charakteristisch angesehenen Verkalkungen der Lunge, der Niere oder der Magenschleimhaut aufweisen, so ergibt die Statistik, dass von 23 sicheren am Meuschen beobachteten Fällen 19 mit ausgedehnter Knochenerkrankung verbunden waren, während diese nur 4 mal [in je einem Fall von Chiari (7), Hláva (21), Kischenski (25) und Stade (46)] bei der Obduktion vermisst wurde ${ }^{1}$ ). Der Gedanke, dass hier ein genetischer Zusammenhang zwischen Knochenerkrankung und Kalkablagerung besteht, drängt sich unabweislich auf. In der Tat besteht zur Zeit nur eine Meinungsverschiedenheit darüber, ob die Knochenerkrankang bezw. die von ibr ausgehende Übersättigung der Gewebe mit Kalk als das primäre, zur Kalkinfiltration führende Moment anzusehen ist (Virchow), oder ob die Gewebsdegeneration unabhängig von der Knochenerkrankung beginnt und nur infolge des rorbandenen verfügbaren Kalküberschusses Kalkeinlagerung erfährt (Kockel [27]). Die Kalkübersättigung wäre in letzterem Falle nur eine „Begleitursache“ und die Kalkmetastase selbst nur eine Form der dystrophischen Verkalkung ${ }^{2}$ ).

Behufs Entscheidung dieser Frage ist festzustellen: 1. ob Kalkübersättigung des Organismus überhaupt zur Kalkablagerung führt, 2. warum sich diese gerade in Gefässen, Lungen und Magen einstellt.

Von experimentellen Untersuchungen in ersterer Richtung liegen zurzeit nur Versuche von v. Kóssa vor, denen zufolge Chlorcalciuminjektion bei

1) Die bis 1901 beschriebenen und zwei selbst beobachtete Fille finden sich bei Askanazy (4) zusammengestellt. Seiner zutreftenden Kritik der unsicheren Falle möchte ich mich durchaus anschliessen. Seitdem ist je ein Fall von Kischenski (25) und von H u ebschmann (23) beschrieben. Überdies gehört hierher ein Befund von Davidsohn (12) an einem Hund, der Säure zugeführt erhalten hatte, und ein von E. Lévy (32) an einem Kaninchen mit Impftuberkulose beobachteter Fall. Anf die in den meisten Fällen beobachteten Verkalkungen in den Nieren ist bei dem überaus hänfigen Vorkommen dieser Veränderung von 35. Lebensjahre ab (vgl. Beer [5]) kein entscheidendes Gewicht zu legen.

2) Kockel sucht an von ihm beobachteten Fällen von Kalkmetastase und Lungenverkalkung den Beweis zu führen, dass embolische und thrombotische Veränderungen in der Lunge Ausgangspunkt der Verkalkung sind. Andere Autoren haben vielfach keine solchen Veränderungen beschrieben oder bezeichnen ausdrucklich die Gefässe als durchgängig. 
Kaninchen an sich keine Kalkablagerung erzeugt, wohl aber die Verkalkung der durch Jodoform geschädigten Leber begünstigt. Indes hat v. Kóssa nur so geringe Mengen Kalksalz injiziert, dass eine erhebliche Steigerung des Kalkgehaltes der Körperfüssigkeiten nicht gegeben war.

Demgegenüber haben zahlreiche über meine Veranlassung von Tanaka ausgeführte Versuche, bei denen verschiedene Kalksalze (Lactat, Acetat, Chlorid, Carbonat, Phosphat) Kaninchen in grösserer Menge beigebracht wurden, regelmässig zu Kalkablagerungen in den der Injektionsstelle benachbarten, öfter auch in fernabliegenden Geweben geführt ${ }^{1}$ ).

Intraperitoneal beigebrachte gelöste Kalksalze - meist wurde Calciumlactat injiziert - verschwanden innerhalb 24 bis 48 Stunden aus der Bauchhöhle restlos. Das Peritoneum zeigte nur geringe Reizung und manchmal zarte fibrinöse Auflagerungen. Vom 2.-3. Tage ab konnte das Auftreten von Kalkinfiltration in dem subserösen Gewebe der Bauchwand bemerkt werden. Später, am deutlichsten nach mehrfacher intraperitonealer Injektion, wurde sehr ausgebreitete Verkalkung der subserösen Gewebe gefunden, während das Peritoneun selbst stets frei blieb. Wie die mikroskopische Untersuchung der in verschiedenen Stadieu getöteten Tiere lehrte ${ }^{2}$ ), erfolgte die Kalkablagerung entweder diffus, oder die Verkalkung erschien auf bestimmte Gewebselemente, vor allem Muskelfasergruppen der Bauchwand und Fettzellen des subserösen Fettgewebes und des Netzes beschränkt. Wurde die Untersuchung sehr spät, 2-3 Monate nach der Iujektion, vorgenommen, so fanden sich Verkalkungen nicht mehr vor.

Die durch Resorption des injizierten Kalksalzes aus der Bauchhöhle eingetretene Kalkinfiltration beschränkte sich nicht anf die Umgebung der Injektionsstelle, sondern betraf, namentlich bei wiederbolter Injektion, die verschiedensten an die Bauchböhle grenzenden Gewebe, Darm, Magen, Zwerchfell, Netz, Lymphdrüsen, wenn auch in sehr wechselnder Ausdehnung. Auffallend stark war nächst der Muskulatur der Bauchwand das subseröse Fettgewebe des Darms betroffen, während Leber, Pankreas, Milzparenchym kaum je verändert angetroffen wurden. In ausgesprochenen Fälen erschien die ganze Bauchhöhle, namentlich aber die äussere Bauchwand panzerartig von einer $1 / 2-1 \mathrm{~mm}$ dicken subserösen Kalkschichte ausgekleidet.

Sehr wichtig ist, dass bei stärkeren Graden der Veränderung sich makroskopisch erkennbare Verkalkungsherde auch im Herzen, der Brust-, der Rücken- und Extremitätenmuskulatur fanden. Es geht daraus hervor, dass die experimentell gesetzte Kalküberschwemmung nicht bloss an den direkt betroffenen Stellen, wo man etwa an eine Koagulierung des Protoplasmas durch konzentriertes Calciumsalz denken könnte, zu Kalkablagerung führte, sondern auch an Stellen, denen der Kalküberschuss nur durch Vermittlung der Blutbahn, also sicher schon in grosser Verdünnung, zugeführt worden war.

1) Hunde und Meerschweinchen verhalten sich, soweit aus der geringeren Zahl von Versuchen ein Schluss gestattet ist, durchans ähnlich.

2) Die histologische Entersuchung wurde im Institut von Prof. Chiari ausgeführt. 
Nach Einbringung von unlöslichen Kalksalzen (Calciumcarbonat und tertiärem Calciumphosphat) in die Bauchhöble waren diese selbst nach Monaten nicht ganz verschwunden. Dass aber doch eine Resorption stattfand, war in den ersten Wochen daran erkennbar, dass die anliegenden Muskelpartien der Bauchwand ziemlich ausgebreitete Verkalkung aufwiesen. Die genannten, in Wasser unlöslichen Kalkverbindungen können somit im Organismus der Lösung unterliegen und an anderer Stelle zur Verkalkung führen.

Verkalkungen der Gefässwand, der Magenschleimhaut und des Lungenparenchyms wurden nicht beobachtet. Doch fanden sich regelmässig hirsekorn- bis linsengrosse Ekchymosen im Fundusteil der Magenschleimbaut.

Die chemische Untersuchung der Kalkablagerungen ergab, dass sie, welches Kalksalz immer beigebracht worden war, aus Calciumphosphat mit wenig Calciumcarbonat bestanden. Nur die Verkalkung des subserösen Fettgewebes beruhte, wie chemisch und tinktoriell nachgewiesen werden konnte, zum Teil auf Ablagerung von Kalkseifen.

Der chemische Vorgang bei der Kalkinfiltration lässt sich danach folgendermassen auffassen. Das in die Bauchhöhle gebrachte gelöste Kalksalz wird rasch von dem subserösen Gewebe aufgenommen, und hier durch Umsetzung mit dem Phosphat und Carbonat der Lymphe und des Blutes unter gleichzeitiger Abgabe von Kohlensäure an das vorbeiströmende Blut diffus zur Abscheidung gebracht. Calciumcarbonat und Calciumphospat kommen nach Lösung durch übersehüssige Kohlensäure auf dem gleichen Wege zur Resorption und fallen im Gewebe, sobald ihnen das vorbeiströmende Blut Kohlensäure entzieht, wieder aus. Da genug Phosphorsäure zur Verfügung steht (wenigstens ist das beim Kaninchen und Hunde der Fall) so erfolgt die Abscheidung hauptsächlich in Form von Phosphat. Während im Beginn der Kalkabscheidung auch die Lymphspalten erfüllt erscheinen, werden diese später wieder frei, wogegen die in Muskelfasern, Bindegewebe usw. abgelagerten Kalkmassen erst nach Wochen verschwinden.

Die Bildung von Verkalkungsherden fern von der Injektionsstelle mitten im sonst normalen Gewebe ist in gleicher Weise zu deuten, nur muss hier, um das umschriebene Auftreten zu erklären, die Anwesenheit örtlich wirksamer prädisponierender Momente angenommen werden.

Die ausgedehnt auftretende Verikalkung des subserösen Fettgewebes weist darauf hin, dass in diesem schon in vita als Kalkfänger wirkende Fettsäuren vorkommen. $\mathrm{Ob}$ es sich dabei um eine physiologische oder, was minder wahrscheinlich, um eine durch die Injektion veranlasste Fettspaltung handelt, ist nicht $\mathrm{zu}$ entscheiden.

Nach dem Ausgeführten steht die Theorie der metastatischen Verkalkung, wie sie Virchow als Folge einer Übersättigung mit Kalksalzen vor- 
schwebte, mit unseren Befunden in Einklang. Es ist das deshalb wichtig, weil bisher für die Kalkmetastasen der direkte chemische Nachweis der Kalküberschwemmung fehlte. Auch solche Fälle, wie z. B. jüngst Nunakawa (34) einen beschrieben hat, wo sich die Kalkablagerung in der Nachbarschaft von Knochenarrosionen fand, sind nach Analogie mit obigen Erfahrungen ohne weiteres verständlich. Die von der Arrosionsstelle abströmende Lymphe, die Kalkphosphat durch Kohlensäure gelöst enthält, lässt das Phosphat ausfallen, sobald sie in ein von arteriellem Blut durchströmtes Gebiet gelangt, wo die Kohlensäure vom Alkali des Blutes gebunden wird.

Hingegen ist die beim Menschen beobachtete merkwürdige Lokalisation der Kalkmetastasen in Gefässwand, Magenmucosa und Lunge dem Verständnis nicht ohne weiteres zugänglich, zumal uns eine experimentelle Nachahmung der pathologischen Vorgänge bisher richt gelungen ist ${ }^{1}$ ).

Auch hier ist die Annabme örtlich wirksamer prädisponierender Momente nicht zu umgehen. Sie können aber gerade bei den typisch betroffenen Organen nicht wohl in einer spezifischen Neigung gewisser Gewebsbestandteile zur Kalkaufnahme gesucht werden, da Magenschleimhaut und Lungengewebe sonst keine besondere Disposition zu ausgedehnter Verkalkung bekunden. Hingegen kann hier ein anderes in jüngster Zeit von Askanazy (4) betontes Moment herangezogen werden. Askanazy hat darauf aufmerksam gemacht, dass die von Kalkmetastase am häufigsten befallenen Organe, Lunge, Magenschleimbaut und Niere, sämtlich saure Sekrete bezw. Kohlensäure abgeben, dadurch eine Alkaleszenszunahme ihrer Gewebsflüssigkeit erfahren und infolgedessen zum Ort der Verkalkung werden können. Es ist bei genauerer Erwägung nicht schwierig zu beurteilen, inwieweit dieser Gedanke bei Magen und Lunge das Richtige trifft. In betreff. der Niere ist das viel schwerer, da einmal die Niere, wie oben erwähnt, überaus häufig Verkalkungen aufweist, da sie ferner nicht bloss als Ausscheidungsstätte eines sauren Sekretes, sondern auch als ein Organ in Betracht kommt, das für Kalksalze und Phosphate behufs Sekretion ein spezifisches Anziehungsvermögen besitzt, das überdies in seiner komplizierten Leistung nicht leicht zu übersehen ist. Hingegen macht die obige Vorstellungsweise das Auftreten von metastatischer Kalkablagerung an einer Stelle wahrscheinlich, auf die früher schon Rindfleisch und $K \ddot{u t t n e r}(30)$ hingewiesen haben, in der Wand der Arterien und der Kapillaren.

Kommt es nämlich durch Resorption von Knochensalzen zu einer Anreicherung daran im Blute, der die Ausscheidung durch Niere und Darm nicht, wie sonst gewöhnlich, das Gleichgewicht hält, dann gibt das Blut den Über-

1) Die oben erwähnten von Davidsohn und E. Lévy mitgeteilten Beobachtungen am Hund and Kaninchen sind Zufallsbefunde. Davidsohns Versuche, durch Säurezufuhr experimentell Kalkmetastasen zu erzeugen, blieben obne Erfolg. 
schuss an die Gewebe ab, so dass es zu einem abnorm hohen Kalkgehalt der Gewebslymphe kommt. Trotz gleichzeitiger Anwesenheit von phosphorsauren Salzen wird der Kalk hier in Lösung bleiben, so lange der Koblensäuregehalt der Lymphe, der in den Geweben höher ist als im venösen Blut, hinreicht, um den über die Löslichkeitsgrenze der Kalkphosphate hinausgehenden Anteil in Lösung zu halten, wobei zu berücksichtigen ist, dass die Lymphe wegen ihres geringeren Eiweissgehaltes nicht so günstige Lösungsbedingungen für Kalkphosphat darbietet, wie das Blut. Die Neutralisation oder die Entziehung der Kohlensäure muss zur Ausscheidung von Kalksalzen führen und da diese Entziehung durch das Blut erfolgt, und zwar den Spannungsverhältnissen entsprechend um so vollständiger, je kohlensäureärmer es ist, so ist zu erwarten, dass es an der Berührungszone zwischen arteriellem Blut einerseits, dem mit Kalksalzen übersättigten Gewebe andererseits zu Kalk. abscheidung komint.

Das lehrt auch eine von mir und Tanaka zur Demonstration dieser Verhältnisse venutzte Versuchsanordnung. Lässt man einen langsamen Strom von $0,1-0,2 \%$ iger Natrium. karbonatlösung bei $37^{\circ}$ durch einen Schilfschlanch fliessen, der in eine Lösung von primärem Calciumphosphat (wir benutzten durch Kohlensäureeinleiten gelöstes Tricalciumphosphat) taucht, so kommt es sehr bald zur Abscheidung ron Kalkphosphat and zwar wird der grössere Teil als äusserst feine Schicht oder in Form von ablösbaren Platten und weissen Pünktchen auf und in der Wand des Schilfschlauches abgelagert.

Dieser Auffassung nach müsste die metastatische Verkalkung besonders die von arteriellem Blut durchströmten Gefässe, Arterien und Kapillaren befallen und vorzugsweise zur Infiltration der Intima führen. Dem entspricht vielfach die Beschreibung der hierher gehörigen Fälle.

So teilt Küttner eine Beobachtung mit, wo infolge von rarefizierender Ostitis der Wirbelsänle sämtliche Arterien in den letzten Lebenswochen verkalkten, während die Venen intakt blieben. Dabei bestand die Kalkablagerung im Gegensatz zu dem Befund bei der senilen Verkalkung vorwiegend in der Ablagerung von feinkörnigen mehr oder weniger stark lichtbrechenden Platten in und auf der Intima, während Media und Adventitia frei oder doch viel weniger betroffen waren. Lé y y (32) beschreibt ferner in seinem Falle (Kaninchen) sehr intensive Verkalkung der Aorta und der Carotiden. Auch die in dem einen Fall Davidsohns (11) beobachtete Kalkplattenbildung an der Mitralklappe, am linken Herzohr und in der Pulmonalvene, dürfte hierber gehören und durch die kohlensäureentziehende Wirkung des arteriellen Blutes auf die mit Kalksalzen gesättigte Gefässwand za erklären sein. ${ }^{1}$ )

Diese Wirkung der Koblensäureabgabe an das durchströmende Blut muss sich in Organen, die ein saures Sekret abgeben, entsprechend stärker geltend machen. Demgemäss treten in den beschriebenen Fällen von Kalkmetastase die Lungen- und Magenveränderungen bei weitem in den Vordergrund.

Unter 16 Fällen, wo die Untersuchung der Lunge vorliegt, fehlt die

1) Das relativ seltene Auftreten von dystrophischer Verkalkung der Venen im Gegensatz zu den Arterien bringt $K u ̈ t$ tner wohl mit Recht ebenfalls in Beziehung zum höheren Kohlensäuregehalt des venösen Blutes. 
Verkalkung der Lunge nur zweimal. Weniger regelmëssig findet sie sich in der Magenschleimhaut, immerhin doch in der Hälfte der darauf untersuchten Fälle. In dem Gewebe der Lunge, wo einerseits an der Alveolarfläche stetig Kohlensäure abgegeben wird, wo andererseits nach erfolgtem Gasaustausch auch das Blut der Kapillaren und der Lungenvenen Kohlensäure zu binden vermag, wo also Säureabgabe nach zwei Seiten erfolgt, findet sich die Verkalkung sowohl längs der Alveolarfläche, als auch an der Aussenfläche der Kapillaren und an der Intima der venösen Gefässe (Czech [10]), gelegentlich auch im interalveolären Bindegewebe (oft unter Verschonung der elastischen Fasern). Bei hochgradiger Veränderung kann das gesamte interalveoläre Gewebe (mit Ausschluss der Gefässe) zu einer starren, glänzenden, beim Schneiden splitternden Kalkmasse umgewandelt sein, wodurch das seit Virchow öfter beschriebene tuffsteinartige Gefüge solcher Stellen zustande kommt.

Die ausgiebigste Säureentziehung, die im Organismus statthat, erfolgt in der Magenschleimhaut. Die Bildung der Salzsäure des Magensafts beruht bekanntlich auf einer Zerlegung der Chloride, wobei die entstehende Salzsäure den Weg zum Mageninhalt, das abgespaltene Alkali den Weg zum Blute einschlägt. Wie stark hier die Säureentziehung ist, geht aus der oft beschriebenen Erscheinung hervor, dass gleichzeitig mit der Sekretion eine Abnahme der Acidität des Harns eintritt (vergl. Schwarz [44]). Danach zu schliessen müssen während der Salzsäuresekretion an der Aussenwand der sezernierenden Drüsen ganz ungewöhnlich günstige Bedingungen zur Bindung von Säure gegeben sein. Da das während der Sekretion reichlich zuströmende arterielle Blut im selben Sinne wirkt, so steht das interglanduläre Gewebe unter dem Einfluss einer doppelten Kohlensäureentziehung. Wenn es mit Kalksalzen übersättigt ist, kann deren Ausfallen in dem adenoiden Gewebe um die Drüsen und um die Kapillaren herum geradezu erwartet werden. Dass diese Kalkablagerung, wie aus den beschriebenen Fällen hervorgeht, nicht so regelmässig gefunden wird, wie in der Lunge, mag damit zusammenhängen, dass die Magensaftsekretion keine kontinuierliche Funktion ist, so dass in den ausgiebigen Sekretionspausen eine Rückbildung der gesetzten Veränderungen erfolgen kann. $(\mathrm{Ob}$ die in Tanakas Versuchen nach Kalkinjektion fast regelmässig beobachteten Ekchymosen in der Magenschleimhaut etwas mit diesen Verhältnissen $\mathrm{zu}$ tun haben, ist noch nicht untersucht.)

Die in der Literatur vorliegenden Beschreibungen der Metastasen im Magen entsprechen überraschend genau der entwickelten Vorstellung. Die Kalkablagerung findet sich stets in dem interglandulären Gewebe, so dass die Drüsen, die selbst unverkalkt bleiben, förmlich in Kalkscheiden stecken. Sie beschränkt sich auf das Fundusgebiet, während Kardia und Pylorus frei- 
bleiben ${ }^{1}$ ) entsprechend der Tatsache, dass die Salzsäurebildung nur in den Fundusdrüsen zustande kommt. Ferner erstreckt sich die Verkalkung nicht auf die ganze Länge der Drüsen, sondern nur auf die oberen Teile (nach Virchow (45) und Schläpfer (40) auf $2 / 3$ der Länge, nach Askanazy (4) und Davidsohn (11) auf den mittleren Teil) was der Anordnung der Belegzellen, denen man geneigt ist die Salzsäurebildung zuzuschreiben, entspricht, da diese dem unteren Drittel der Fundusdrüsen abgehen ${ }^{2}$ ).

Wie aus dem Gesagten hervorgeht, lässt sich Virchows mit genialem Scharfblick konzipierte Lebre der Kalkmetastasen mit den physiologischen Tatsachen gut in Einklang bringen. Für die Vorstellung, dass es sich auch hier nur um Verkalkung vorher degenerierter Gewebe handelt, ist kein Beweis erbracht. Denn die Tatsache, dass öfter in den verkalkten Partien degenerative Vorgänge nachweisbar waren, kann nicht viel beweisen, da es. sich um Folgeerscheinungen handeln konnte. Ebensowenig kann das gleichzeitige Vorkommen von typischer dystrophischer Verkalkung an anderen Stellen als Einwand gelten, da die Kalküberschwemmung unabbängig davon eintretende degenerative Vorgänge nicht ausschliesst und die nachfolgende Verkalkung der degenerierten Stellen geradezu begünstigen muss.

Der öfter geltend gemachte Einwand, dass in einem kleinen Teil der beobachteten Falle von typischer Kalkmetastase eine makroskopisch diagnostizierbare Knochenerkrankung fehlte, hat in jüngster Zeit dadurch an Gewicht verloren, dass Askanazy und sein Schüler Lévy in 2 Fällen nachweisen konnten, dass sich das makroskopisch anscheinend intakte Skelett bei mikraskopischer Untersuchung weitgehend im Sinne einer progressiven Knochenatrophie verändert erwies.

Aber selbst, wenn man zugibt, dass typische Kalkmetastasierung ohneKnochenerkrankung vorkommt, ist die Virchowsche Lehre nicht widerlegt, da, wie Aschoff (3) mit Recht betont, unsere Kenntnis des Kalkstoffwechsels nicht dazu berechtigt, in solchen Fällen eine Kalkübersättigung auszuschliessen. An Kalkretention infolge der meist nachweisbaren Nierenveränderung ist schon von Virchow gedacht worden, aber auch eine Verminderung der Kalkausscheidung durch den Darm kann in Frage kommen (zumal gelegentlich auch Verkalkungen in der Darmschleimhaut gefunden: worden sind), ebenso eine abnorm reichliche Kalkaufnahme vom Darm aus, sei es wegen Zufuhr allzu kalkreicher Nahrung, sei es wegen abnormer der Kalkresorption im Darm besonders günstiger Bedingungen.

1) Virchow (45). Roth (39) gibt an, in seinem Fall in der Pars pylorica Verkalkungen gesehen zu haben, doch war diese nicht normal gebaut (Polypen), und es bleibt fraglich ob. dort Pylorus- oder Fundusdrüsen vorlagen.

2) Den gleichen Gedanken deutet wohl E. Lévy an, indem er bemerkt, dass sich aus dex Vorstellung Askanazys erklärt, warum sich die Verkalkung des Stromas nicht auf die ganze Länge der Drüsen erstreckt. 


\section{Die Zusammensetzung verkalkter Gewebe.}

Wie oben erwähnt, entspricht die Zusammensetzung der pathologischen Kalkablagerungen vielfach sehr nahe jener der Knochenasche ${ }^{1}$ ).

So fand Wells im Glührückstand verkalkter Gewebe und zwar:

in tuberkulösen Lymphdrüsen vom Rind

$"$ "
$"$

\begin{tabular}{|c|c|c|}
\hline $\mathrm{Ca}_{3}\left(\mathrm{PO}_{4}\right)_{2}$ & $\mathrm{CaCO}_{4}$ & $\mathrm{Mg}_{3}\left(\mathrm{PO}_{4}\right)_{2}$ \\
\hline $85,9^{\circ} / 0$ & $12,8^{\circ} \%$ & $0,84^{\circ} \%$ \\
\hline 85,4, & 13,1 & 0,9 \\
\hline 86,4, & 11,7 & 1,2 \\
\hline 87,8, & 10,1 & 1,2 \\
\hline 85,4 & 13,4 & 0,85 \\
\hline 86,5, & 11,9 & 1,1 \\
\hline
\end{tabular}

Die von $\mathrm{Z}$ alesky und Carnot ermittelten Zahlen für Menschenund Rindsknochen sind: $\mathrm{Ca}_{3}\left(\mathrm{PO}_{4}\right)_{2} 83,8-87,8 \%, \mathrm{CaCO}_{3} 9,2-12,8 \%, \mathrm{Mg}_{3}\left(\mathrm{PO}_{4}\right)_{2}$ $1,02-1,75 \%$.

Diese auffällige Übereinstimmung scheint darauf hinzuweisen, dass die physiologische und pathologische Verkalkung auf der Bildung einer bestimmten chemischen Verbindung beruht. Das Verhältnis von Phosphorsäure und Kohlensäure zum Calcium, wie es sich beim Knochen durchschnittlich findet, lässt sich nach $\mathrm{H}$ op p e-Seyler unter Vernachlässigung der übrigen allerdings nur spärlich vertretenen anorganischen Bestandteile annähernd durch die Formel $3\left(\mathrm{Ca}_{3} \mathrm{P}_{2} \mathrm{O}_{8}\right) \mathrm{CaCO}_{3}$ ausdrücken. Danach könnte es scheinen, als ob die Verkalkung im wesentlichen auf der Abscheidung dieser sonst nicht dargestellten Verbindung beruhte. S. Gabriel (16) findet den einfachsten Ausdruck für die Zusammensetzung und die Eigenschaften der Knochen- und Zahnasche in der Formel $\left[\mathrm{Ca}_{3}\left(\mathrm{PO}_{4}\right)_{2}+\mathrm{Ca}_{3} \mathrm{HP}_{3} \mathrm{O}_{13}+\mathrm{aq}\right]$, wenn in ihr 2-3\% Kalk durch Magnesia, Kali, Natron und 4-6\% Phosphorsäure durch Kohlensäure, Chlor, Fluor vertreten sind. Überdies hat Gabriel ermittelt, dass das Calciumphosphat des Knochens in zwej Formen, einer in Ammoncitrat löslichen und einer darin unlöslichen, vorhanden ist. Dieser komplizierten Vorstellung gegenüber liegt der Gedanke nahe, dass es sich bei der Ablagerung der Erdalkalisalze im Knochen nicht um eine einzelne, bestimmte, allenfalls von verwandten Salzen verunreinigte, chemische Verbindung handelt, sondern um ein Gemenge solcher Verbindungen und zwar in einem quantitativen Verhältnis, das von den im Organismus gegebenen Bedingungen abhängt. Die beobachtete Konstanz der Zusammen. setzung wäre darnach nicht bedingt durch die Bildung einer bestimmten chemischen Verbindung, sondern durch die Kon-

1) Die Kalkablagerungen, die zum Teil aus Kalkseifen bestehen, zeigen, da es sich um wechselnde Gemenge beider Verkalkungstypen handelt, kein einheitliches Verhalten. 
stanz der bei der Verkalkung gegebenen chemischen Bedingungen.

Für diese Vorstellung lässt sich folgendes anführen. Ausschlaggebende Bedingung muss die Zusammensetzung der umspülenden Gewebsflüssigkeit sein, namentlich ihr Gehalt an Kalk, Magnesia, Phosphorsäure und Kohlensäure. Mit diesem muss sich die anorganische Substanz des Knochens oder des Verkalkungsherdes, die ja nach dem oben ausgeführten in stetem Abbau und Wiederaufbau begriffen ist, gewissermassen im Gleichgewicht halten.

Den Einfluss der Gewebsflüssigkeit auf die Zusammensetzung der im Knochen vorhandenen unlöslichen Kalksalze hat nun Tanaka bei mir in der Weise geprüft, dass er einerseits Calciumcarbonat, andererseits Calciumphosphat in die Bauchhöhle von Kaninchen brachte, nach einiger Zeit wieder sammelte und analysierte. Es zeigte sich, dass das Calciumcarbonat zu einem Teil in Phosphat, umgekehrt das Phosphat zu einem Teil in Carbonat umgewandelt war. Die Umwandlung des Carbonats zu Phosphat betrug in den ersten Tagen 0,6-0,9\% des angewandten Kalksalzes in 24 Stunden. Da sich dieser Vorgang auch, weungleich etwas träger, vollzog, wenn das be. treffende Kalksalz im Schilfschlauch eingeschlossen in die Bauchhöhle eingebracht wurde, so konnte es sich nicht um eine Mitwirkung geformter Elemente oder auch um Eindringen von Kalkeiweissverbindungen des Blutes, sondern nur um eine durch Diffusion vermittelte chemische Umsetzung bandeln.

Versuche in vitro, wo Tricalciumphosphat in Schilfschläuchen wochenund monatelang der Einwirkung von sehr verdünnter Sodalösung bei $37^{\circ}$ ausgesetzt blieb, ergaben, dass der Endzustand dieser Umsetzung von der Konzentration der Lösung abhängt. Das Verhältnis von Calciumphosphat zu Calciumcarbonat ergab sich bei Einwirkung einer $0,1 \%$ igen Sodalösung zu $90,65 \%: 9,23 \%$, bei Einwirkung einer $0,3 \%$ igen Lösung zu 84,09\%:17,38\%. In einem Versuch, wo Tricalciumphosphat in Nachahmung der im Organismus gegebenen Verhältnisse 12 Tage der Einwirkung einer Lösung von $0,9 \% \mathrm{NaCl}, 0,1 \% \mathrm{Na}_{2} \mathrm{CO}_{3}$ und $0,1 \% \mathrm{NaHCO}_{3}$ bei $37^{\circ}$ ausgesetzt war, enthielt der Niederschlag auf $85,2 \%$ Calciumphospat $12,75 \%$ Calciumcarbonat, Zablen die sich der Zusammensetzung des Knochens ausserordentlich nähern.

Bei pathologischen Verkalkungen hat man allerdings nicht immer die Übereinstimmung der Zusammensetzung mit jener der Knochenerde gefunden, wie sie sich aus dew oben angeführten Analysen von Wells ergibt ${ }^{1}$ ).

1) So fand z. B. Wells selbst in einer verkalkten aber in Erweichung begriffenen Lymphdrüse 90,6\% $\mathrm{Ca}_{3}\left(\mathrm{PO}_{4}\right)_{2}$ neben nur 7,6\% $\mathrm{CaCO}_{3}$ und $1,5 \% \mathrm{Mg}_{3}\left(\mathrm{PO}_{4}\right)_{2}$, Gascard (17) in einer subkutanen Konkretion 88,4 Teile $\mathrm{Ca}_{3}\left(\mathrm{PO}_{4}\right)_{2}$ auf 8,9 Teile $\mathrm{CaCO}_{3}$, Harley (20) in einer verkalkten fibrösen Geschwnlst 74,6 Teile $\mathrm{Ca}_{3}\left(\mathrm{PO}_{4}\right)_{2}$ auf 18,9 Teile $\mathrm{CaCO}_{3}$ usw. Übrigens ist von Wildt (53) u. a. anch ein geringer Einfluss des Alters auf die Zusammensetzung des normalen Knochens und zwar im Sinne einer Zunahme der Kohlensäure und einer Abnahme der Phosphate nachgewiesen. Eine Anderung in gleichem Sinne aber in viel grösserem Umfang ist von W. Biedermann für Molluskenschalen beschrieben. 
Diese Abweichungen sind sehr schwer verständlich, wenn man annimmt, dass die Verkalkung auf der Bildung einer bestimmten chemischen Verbindung beruht, während sie sich bei obiger Auffassung ohne weiteres aus dem Umstande erklären, dass die örtlichen Bedingungen der Verkalkung je nach der Lage und dem Substrat des Herdes recht versehieden sein müssen. Es ist anzunehmen, dass sich dieser örtliche Einfluss namentlich im Anfang geltend gemacht, und dass länger bestehende Verkalkungsherde sich durch den Stoffaustausch mit dem umspülenden Blut in ihrer Zusammensetzung immer mehr dem Typus der Knochenerde nähern. 